AUTHOR POST-PRINT Copyright Springer-Verlag Berlin Heidelberg, Germany.

The original publication is available at www.springerlink.com

Original source of publication:

R. Wichert, K. Van Laerhoven, \& J. Gelissen (Eds.), Constructing Ambient Intelligence: AmI 2011 Workshops. Revised Selected Papers (p. 163-165). Berlin: Springer CCIS Series. ISBN 978-3-642-25166-5.

\title{
Technology and Aging: Inhibiting and Facilitating Factors in ICT Use
}

\author{
Anja Leist ${ }^{1}$, Dieter Ferring ${ }^{1}$ \\ ${ }^{1}$ University of Luxembourg, FLSHASE, Route de Diekirch, L-7220 Walferdange, Luxembourg \\ \{Anja.Leist, Dieter.Ferring\}@,uni.lu
}

\begin{abstract}
Extending a literature review, the paper gives an overview of inhibiting and facilitating factors associated with the use of information and communications technology (ICT) of older adults. The paper takes the position that there is no prototypical "elderly user" but that there is a wide heterogeneity of personal characteristics such as cognitive and motivational states and experiences in old age. Dependent upon various characteristics of the elderly user as well as the context of application, development and implementation of ICT should follow the desideratum of a differential technology implementation taking an integrative approach by reconciling individual and social as well as socio-political approaches.
\end{abstract}

Keywords: ICT - technology use - elderly users - psychological factors

\section{Introduction}

Despite the evident benefits of modern technologies both on the personal as well as on the societal and economic level, technology solutions do not receive unequivocal acceptance by the potential end users. Since acceptance is directly linked to technology use, it is thus the essential characteristic of user experience. Technology acceptance is predetermined by several factors both at the individual as well as the societal level. Here, we will focus on the characteristics of the "elderly user" on the individual level without neglecting that the interaction of individual characteristics, the context of technology application, and the larger societal context may also play a significant role in explaining differences in individual use. Moreover, we will narrow the focus to the use of information and communications technology (ICT).

\section{The "Elderly ICT User"}

Despite the broad consensus that ICT in its various manifestations will bring benefits to elderly persons, there are at least three perseverant myths holding that elderly users show several limitations that can inhibit the use of these technologies [1]. The first myth concerns the level of interest and negative attitudes towards technology in elderly adults. Although there is evidence that older adults use information and electronic technology less often than other age groups, interest and willingness to acquire new ICT-related skills characterize the major part of older adults. A second myth concerns the learning capacity of elderly persons, assuming to be limited due to decline in cognitive performance. Here, there is evidence that the young-old (age 60 to 74) and the old-old (age 75 and above) can readily acquire computer skills, navigate Web sites and maintain these skills over time [2]. Evidently, the most important factor within this context is the availability of training and continuous support of the elderly novice user [3]. Finally, a third myth holds that negative attitudes and anxiety may impact computer task performance of older adults. Results of several intervention studies are in favor of the benefits of training programs, showing that experience and training diminish anxiety [4].

These general findings may give the impression that there is some kind of a prototypical elderly ICT user; however this would simplify the heterogeneity of attitudes, motivational states, and experiences which constitute 
individuals in old age. In a representative European sample, the following typology of elderly ICT users was derived: (1) the experienced front runners who benefit from a lifelong expertise of computer use, (2) the old age beginners who use the computer less often than once a week, (3) the technologically open-minded non-users that are keen on learning about technology or wish to improve computer skills, and (4) the digitally challenged non-users who are not interested in learning or improving computer skills [5]. Whereas this user typology mainly relies on the factors 'technology experience' and 'current technology use', we postulate that various other characteristics also promote or hinder the use of ICT at the individual level. Some of the factors that have proven to be important in this context will be described in the following.

\section{Inhibiting and Facilitating Factors of ICT Use - What We Know so Far}

Earlier research has identified important user characteristics from a psychological point of view [6]. We will extend this line of thinking in suggesting to combine these characteristics in order to elaborate differential user profiles. When it comes to explaining differences in ICT use, it is important to underline that differences can be inter- as well as intra-individual: There are differences between individuals and one person may also show different profiles across time. Table 1 lists a non-exhaustive overview of several domains and indicators that are associated with differential ICT use at the individual level and may explain both kinds of differences.

The list starts with general demographic characteristics. Throughout the literature, high age, low educational attainment and low socio-economic status (SES), as well as being female are discussed as central features associated with low ICT use in old age. Although chronological age as a proxy of different functional and physical conditions may go along with a decrease in technology use, it is noteworthy that functional restrictions and age are not related to the interest in ICT. Moreover, cohort effects and the underlying different levels of expertise, knowledge and habits have more predictive validity for differences in ICT use than chronological age.

Table 1: Inhibiting and Facilitating Factors of ICT Use on the Individual Level

\begin{tabular}{ll}
\hline Domain & Exemplary Indicators \\
\hline Demographics & Age, SES, education, gender \\
Physical and Functional Status & $\begin{array}{l}\text { Visual and hearing impairments, } \\
\text { morbidity and comorbidities }\end{array}$ \\
Performance Issues & Motor function, eye-hand coordination \\
Cognitive Status & $\begin{array}{l}\text { Information processing } \\
\text { (Perception - Attention - Memory) }\end{array}$ \\
Motivational Factors & ICT-related personal goals and motives \\
Personality Traits & Self-efficacy beliefs, control beliefs \\
Life Story & ICT-related autobiographical memories \\
& Technology experience \\
Social Cognition & $\begin{array}{l}\text { ICT-related attitudes and beliefs } \\
\text { Openness to ICT use }\end{array}$ \\
\hline
\end{tabular}

Besides demographic characteristics, differences in physical and functional status represent a further and evident category. This domain comprises visual and hearing impairments with their direct impact on ICT use as well as more systemic characteristics such as morbidities and comorbidities. Linked to this, we would also like to underline the importance of performance issues such as motor function including the coordination of fine and gross motor skills as further pre-determinants of ICT use. The cognitive domain and here the process of information processing is listed as a further central complex that explains differential ICT use. Information 
processing describes the interplay between attention, perception, and memory and thus the encoding and retrieval of information. All these processes play a dominant role in lifelong ICT use as well as in old age; it is also well documented that the speed of information processing decreases with age, although there are considerable interindividual differences. Impairments in attention span, perception or memory lead to a decreased efficiency in information processing and might thus hinder both the acquisition and application of knowledge on ICT use. Thus, information processing might even be considered as prerequisite for ICT use. Motivational factors are essential for both the short- and long-term commitment to technology use. We would like to underline the importance of individual needs for a given technology application: Only if the application serves - or is perceived as serving - a personal need, the person will be motivated to use a specific device or application. This notion exceeds the user gratification approach, since it considers both explicit and implicit motives and the fact that various different personal goals may underlie the use of a given specific application. Of course, for motivational factors to influence ICT use, the user needs basic knowledge about the functions and handling of a technology device, given that many users state that (a) they do not know why they should use a given tool or (b) they do not know that a given tool may serve a specific need. Personality traits as stable interindividual differences in specific dimensions are illustrated by self-efficacy and control beliefs, which represent central dimensions of ICT use: Only if a person believes that he or she can handle technology applications or that these will have an effect on his or her life, the person will be motivated to use specific technologies. Another domain represents the individual's life story. Here, we subsume autobiographical memories linked to ICT use and technology experience as the result of a lifelong learning history of technology use. Lastly, the domain of social cognition comprises all ICT-related attitudes and beliefs, stereotypes, and the general openness to ICT use. All these personal characteristics have shown to explain differences in ICT use in older adults.

\section{Conclusion: The Need for a Differential Approach to ICT Use}

Taken together, these factors represent important predictors of ICT use on the individual level, though factors might be of differential importance, interact in complex ways, or even counterbalance one another. High age, low education, and low SES characterize conditions of low ICT use despite a good functional status. However, even with major physical impairments, a person with high self-efficacy and control beliefs feeding upon a lifelong technology experience may be a frequent user. Both examples underline the importance of fine-grained differential user profiles to explain interindividual differences in ICT use. In knowing about different user profiles, technology applications in different fields (e.g., virtual coaching) can be manufactured accordingly to maximize user acceptance.

\section{$5 \quad$ References}

1. Rogers, W.A, Mayhorn, C.B., \& Fisk, A.D.: Technology in everyday life for older adults. In Burdick, D. C. \& Kwon, S. (eds.) Gerotechnology: Research and practice in technology and aging, pp. 3-18. Springer, New York (2004)

2. Morrell, R. W., Mayhorn, C. B., \& Echt, K. V.: Why older adults use and do not use the internet. In: Burdick, D. C. \& Kwon, S. (eds.) Gerotechnology: Research and practice in technology and aging, pp. 3-18. Springer, New York (2004)

3. Ferring, D., et al.: Inhibiting and facilitating factors in ICT use in old age: A review (in preparation).

4. Kelley, C. L., \& Charness, N.: Issues in training older adults to use computers. Behaviour and Information Technology, $14,107-120(1995)$.

5. Stroetmann, V. N., Hüsing, T., Kubitschke, L., \& Stroetmann, K. A.: Attitudes, expectations and needs of older people for telehealth: Results from the European SeniorWatch survey. (2002) Derived on November 8th, 2011, from http://www.seniorwatch.de/download/ presentations/SWA_Telemed2002.pdf

6. Oppenauer, C., Preschl, B., Kalteis, K., \& Kryspin-Exner, I.: Technology in old age from a psychological point of view. In A. Holzinger (Ed.): USAB 2007, LNCS 4799, p. 133-142. Springer, Heidelberg (2007) 